UDC 616.127-005.8-053.7-02

DOI: $10.21668 /$ health.risk/2021.3.16.eng

Research article

\title{
RISK FACTORS PROFILE FOR MYOCARDIAL INFARCTION: FOCUS AT A YOUNG AGE
}

\author{
I.A. Novikova ${ }^{1}$, O.V. Khlynova ${ }^{2}$, L.A. Nekrutenko² \\ ${ }^{1}$ S.G. Sukhanov's Federal Center of Cardiovascular Surgery, 35 Marshala Zhukova Str., Perm, 614013, \\ Russian Federation \\ ${ }^{2}$ Perm State Medical University named after Academician E.A. Wagner, 26 Petropavlovskaya Str., Perm, 614094, \\ Russian Federation
}

The paper focuses on examining peculiarities of risk factors causing cardiac infarction at a young age. Although cardiac infarction primarily occurs among patients older than 45, its frequency at a young age has been growing recently. Risk factors that cause cardiac infarction at a young and old age are quite different. Examining risk factors profiles in different age groups provides wider opportunities for implementing primary and secondary prevention strategies aimed at reducing frequency and negative outcomes of ischemic heart disease.

108 patients aged from 18 to 45 and 35 patients aged from 60 to 75 took part in the research; they all had confirmed cardiac infarction with or without rise in ST segment and were treated in a regional center for cardiovascular pathology treatment in a period from January 01, 2017 to January 01, 2019. Basic risk factors of cardiac infarction were assessed when a patient was admitted to a clinic for treatment.

The research results indicate high prevalence of risk factors that could cause ischemic heart disease among young patients. $92.2 \%$ young patients have dyslipidemia, $70.2 \%$ smoke, $68.5 \%$ have low physical activity, $68.2 \%$ suffer from overweight and obesity, $58.8 \%$ have arterial hypertension, $7.4 \%$ suffer from type II pancreatic diabetes, and disorders in tolerance to carbohydrates was reveled in $15.7 \%$ cases. Such factors as male sex (85.2 vs. $37.1 \%, p=0,000)$, smoking (70.2 vs. $20.6 \%, p=0.000)$ and burdened heredity as per early ischemic heart disease occurrence $(54.6$ vs. $16.0 \%, p=0.001)$ were significantly more frequent among young patients than among older ones.

Data obtained via the present research allowed creating risk factors profile for cardiac infarction associated with cardiac infarction occurrence at a young age; this profile included such factors as male sex, early ischemic heart disease occurrence in family history, and smoking

Key words: ischemic heart disease, cardiac infarction, young age, risk factors, smoking, male sex, burdened heredity, primary prevention.

Introduction. Ischemic heart disease (IHD) still occupies a leading position in the structure of morbidity and mortality in the population all over the world [1]. Myocardial infarction (MI) is the most lethal form of IHD and can manifest, among other things, as sudden cardiac death. Despite the fact that MI mainly occurs in patients older than 45 years, in recent years its frequency at a young age has been increasing [2]. The consequences of MI at a young age can be devastating because of the potential impact on psychosocial status and work ability. The pathogenesis of cardiovascular diseases is among the most complex ones due to the interactions between numerous factors including genetics, lifestyle and environment which have a direct impact on a moment of time when the disease starts to develop, its manifestation, localization, severity of the lesion and outcome. The INTERHEART study showed that nine traditional risk factors such as dyslipidemia, smoking, arterial

(C) Novikova I.A., Khlynova O.V., Nekrutenko L.A., 2021

Irina A. Novikova - Cardiologist (e-mail: Nurdus@yandex.ru; tel.: +7 (342) 239-87-87; ORCID: http://orcid.org/00000002-3968-6498).

Olga V. Khlynova - Corresponding Member of the RAS, Doctor of Medical Sciences, Professor, Head of the Department for Hospital Therapy and Cardiology (e-mail: olgakhlynova@mail.ru; tel.: +7 (342) 239-31-88; ORCID: https://orcid.org/0000-0003-4860-0112).

Ludmila A. Nekrutenko - Doctor of Medical Sciences, Professor at the Department for Hospital Therapy and Cardiology (e-mail: lunekru@mail.ru; tel.: +7 (342) 239-31-88; ORCID: http://orcid.org/0000-0001-9151-8195). 
hypertension, diabetes mellitus, obesity, unhealthy diet, low physical activity, alcohol abuse and psychosocial stress explain the development of more than $90 \%$ of all MI cases [3]. However there is evidence that the risk factors that cause MI in young and old age differ [4]. Studies focusing on investigating the characteristics of myocardial infarction in young patients are scattered and few. Studies on risk factor profiles in different age groups provide wider possibilities for implementing primary and secondary prevention strategies aimed at reducing the burden of IHD.

The aim of the study is to identify the characteristics of the risk factors profile for MI at a young age.

Materials and methods. The study included 143 patients with a confirmed diagnosis of MI with and without ST segment elevation who were admitted to the regional vascular center from January 01, 2017 to January 01, 2019. The patients were divided into two groups. The group of young people consisted of 108 patients aged from 18 to 45 , the group of elderly people, 35 patients aged from 60 to 75. The exclusion criteria were: acute diseases, exacerbation of chronic diseases, severe concomitant somatic pathology, type 1 diabetes mellitus, mental illness, and dementia. All patients included in the study gave their voluntary informed consent to participate in it. The characteristics of the patients included in the study are presented in Table 1.

All patients underwent a complete clinical examination including collection of anamnesis data, physical examination, complete blood count, biochemical analysis, coagulation testing, and assessment of urinary albumin excretion. An original questionnaire was used to study the prevalence of traditional risk factors.
Statistical data analysis was carried out using IBM SPSS Statistics v.23 software. Quantitative indicators were assessed for compliance with the normal distribution using the Kolmogorov - Smirnov test as well as indicators of asymmetry and kurtosis. Quantitative indicators that had a normal distribution were represented by the arithmetic mean $(M)$ and standard deviation $(S D)$. Quantitative indicators whose distribution differed from normal were represented by the median $(M e)$ and lower and upper quartiles (Q1-Q3); nominal data, by absolute values and percentages. Mean values in the case of a normal distribution were compared by calculating the Student's t-test, in the absence of a normal distribution, the Mann - Whitney U-test. The nominal data were compared using the Pearson $\chi^{2}$-test. Differences in indicators were considered statistically significant at the significance level being $p<0.05$.

Results and discussion. Men prevailed among young patients with MI compared with the elderly ones. Young patients smoked 3.5 times more often, they had a family history of early-onset IHD 3.4 times more often than elderly patients. In Arterial hypertension was 1.5 times more common and type 2 diabetes mellitus 4 times more common among elderly people. In both groups the majority of patients led a sedentary lifestyle, were overweight and obese, almost all had dyslipidemia (Table 2).

According to the biochemical analysis of blood elderly patients had a lower glomerular filtration rate. The groups of young and elderly patients did not differ in terms of blood lipid spectrum indicators. In both groups there was an increase in the level of total cholesterol and low-density lipoproteins (LDLP) (Table 3).

Table 1

Characteristics of young and elderly patients with myocardial infarction

\begin{tabular}{|l|c|c|c|}
\hline \multicolumn{1}{|c|}{ Parameter } & $\begin{array}{c}\text { Young patients } \\
(n=108)\end{array}$ & $\begin{array}{c}\text { Elderly patients } \\
(n=35)\end{array}$ & $p$ \\
\hline ST-elevation myocardial infarction, $n(\%)$ & $91 / 108(84.3)$ & $16 / 35(48.5)$ & 0.000 \\
\hline Non-ST-elevation myocardial infarction, $n(\%)$ & $17 / 108(15.7)$ & $17 / 35(51.5)$ & 0.000 \\
\hline Age, years $M e(Q 1-Q 3)$ & $41.0(38.0-43.0)$ & $67.5(64.0-71.3)$ & 0.000 \\
\hline
\end{tabular}


Traditional risk factors for myocardial infarction in young and elderly patients

\begin{tabular}{|l|c|c|c|}
\hline \multicolumn{1}{|c|}{ Parameter } & $\begin{array}{c}\text { Young patients } \\
(n=108)\end{array}$ & $\begin{array}{c}\text { Elderly patients } \\
(n=35)\end{array}$ & $p$ \\
\hline Male, $n(\%)$ & $92 / 108(85.2)$ & $13 / 35(37.1)$ & 0.000 \\
\hline Female, $n(\%)$ & $16 / 108(14.8)$ & $22 / 35(62.9)$ & 0.000 \\
\hline Arterial hypertension, $n(\%)$ & $57 / 97(58.8)$ & $30 / 34(88.2)$ & 0.002 \\
\hline Dyslipidemia, $n(\%)$ & $83 / 90(92.2)$ & $31 / 31(100.0)$ & 0.110 \\
\hline Normal weight, $n(\%)$ & $34 / 107(31.8)$ & $8 / 28(28.6)$ & 0.106 \\
\hline Overweight, $n(\%)$ & $47 / 107(43.9)$ & $7 / 28(25.0)$ & 0.069 \\
\hline Obesity (Class I), $n(\%)$ & $17 / 107(15.9)$ & $10 / 28(35.7)$ & 0.020 \\
\hline Obesity (Class II), $n(\%)$ & $8 / 107(7.5)$ & $3 / 28(10.7)$ & 0.578 \\
\hline Obesity (Class III), $n(\%)$ & $1 / 107(0.9)$ & $0 / 28(0.0)$ & 0.608 \\
\hline Premature coronary heart disease in family history, $n(\%)$ & $53 / 97(54.6)$ & $4 / 25(16.0)$ & 0.001 \\
\hline Sedentary lifestyle, $n(\%)$ & $74 / 108(68.5)$ & $22 / 33(66.7)$ & 0.842 \\
\hline Smoking, $n(\%)$ & $73 / 104(70.2)$ & $7 / 34(20.6)$ & 0.000 \\
\hline Diabetes mellitus type 2, $n(\%)$ & $8 / 108(7.4)$ & $10 / 34(29.4)$ & 0.000 \\
\hline Prediabetes, $n(\%)$ & $17 / 108(15.7)$ & $1 / 34(2.9)$ & 0.051 \\
\hline
\end{tabular}

Table 3

Biochemical parameters in young and elderly patients with myocardial infarction

\begin{tabular}{|l|c|c|c|}
\hline \multicolumn{1}{|c|}{ Parameter } & $\begin{array}{c}\text { Young patients } \\
(n=108)\end{array}$ & $\begin{array}{c}\text { Elderly patients } \\
(n=35)\end{array}$ & $p$ \\
\hline $\begin{array}{l}\text { Glucose, } \mathrm{mmol} / \mathrm{L} \\
M e(Q 1-Q 3)\end{array}$ & $5.6(5.2-6.2)$ & $5.8(5.2-7.1)$ & 0.288 \\
\hline $\begin{array}{l}\mathrm{Creatinine}, \mu \mathrm{mol} / \mathrm{L} \\
M e(Q 1-Q 3)\end{array}$ & $81.0(71.0-91.0)$ & $81.5(69.3-98.8)$ & 0.445 \\
\hline $\begin{array}{l}\text { Glomerular filtration rate, } \mathrm{mL} / \mathrm{min} / 1.73 \mathrm{~m}^{2} \\
M e(Q 1-Q 3)\end{array}$ & $108.0(96.0-116.0)$ & $80.5(66.0-89.8)$ & 0.000 \\
\hline $\begin{array}{l}\text { Total cholesterol, } \mathrm{mmol} / \mathrm{L} \\
(M \pm S D)\end{array}$ & $5.0 \pm 1.2$ & $5.3 \pm 1.3$ & 0.207 \\
\hline $\begin{array}{l}\text { Low-density lipoproteins, } \mathrm{mmol} / \mathrm{L} \\
(M \pm S D)\end{array}$ & $3.1 \pm 1.1$ & $3.4 \pm 1.0$ & 0.179 \\
\hline $\begin{array}{l}\text { High-density lipoproteins, } \mathrm{mmol} / \mathrm{L} \\
M e(Q 1-Q 3)\end{array}$ & $1.1(0.8-1.3)$ & $1.2(0.9-1.4)$ & 0.396 \\
\hline $\begin{array}{l}\text { Triglycerides, } \mathrm{mmol} / \mathrm{L} \\
M e(Q 1-Q 3)\end{array}$ & $1.3(0.9-2.1)$ & $1.2(0.8-1.6)$ & 0.352 \\
\hline
\end{tabular}

Table 4

Hemostatic system indicators in young and elderly patients with myocardial infarction

\begin{tabular}{|l|c|c|c|}
\hline \multicolumn{1}{|c|}{ Parameter } & $\begin{array}{c}\text { Young patients } \\
(n=108)\end{array}$ & $\begin{array}{c}\text { Elderly patients } \\
(n=34)\end{array}$ & $p$ \\
\hline $\begin{array}{l}\text { Fibrinogen, g/L } \\
M e(Q 1-Q 3)\end{array}$ & $3.0(2.5-3.6)$ & $3.3(2.7-4.0)$ & 0.146 \\
\hline $\begin{array}{l}\text { Adenosine diphosphate-induced platelet } \\
\begin{array}{l}\text { aggregation, sec } \\
M e(Q 1-Q 3)\end{array}\end{array}$ & $8.0(6.0-10.0)$ & $7.0(6.0-7.0)$ & 0.355 \\
\hline
\end{tabular}

High urinary albumin excretion was observed in $74.1 \%$ of cases among young patients; among elderly ones, in $58.3 \%$; this difference was statistically insignificant $(p=0.164)$.

Examination of the haemostatic system revealed an increase of adenosine diphosphate- induced platelet aggregation in both young and elderly patients (Table 4).

Thus, the results of the study demonstrate high prevalence of risk factors for IHD at a young age: $92.2 \%$ of young patients have dyslipidemia; $70.2 \%$ smoke; $68.5 \%$ lead 
a sedentary lifestyle; $68.2 \%$ are overweight and obese; they have arterial hypertension in $58.8 \%$ of cases; type 2 diabetes mellitus, in $7.4 \%$; prediabetes, in $15.7 \%$. Also in $74.1 \%$ of cases there is high excretion of albumin in urine, which is a marker of endothelial dysfunction and early vascular aging. An increase in adenosine diphosphate-induced platelet aggregation was noted upon admission of patients to the clinic which indicates a thrombophilic status in vascular-thrombocyte homeostasis.

Male gender ( $85.2 \%$ vs. $37.1 \%, p=0.000)$, smoking (70.2 \% vs. $20.6 \%, p=0.000)$ and family history of premature IHD (54.6\% vs. $16.0 \%$, $p=0.001)$ were more common among all risk factors in the cohort of young patients compared with the elderly.

Our data are consistent with the results by W.P. Zhang et al. They also rank smoking and a family history of premature IHD among the most significant risk factors for MI in young patients. The authors noted significantly lower prevalence of arterial hypertension and type 2 diabetes mellitus in the cohort of young patients compared with the elderly which was also consistent with our data. At the same time in this study young patients had higher levels of LDLP and triglycerides and lower levels of high density lipoprotein (HDLP) [5]. According to our data there were no statistically significant differences in lipid spectrum indicators between the groups of young and elderly patients. B.D. Hoit et al. also noted smoking, family history of premature IHD and male gender as the main risk factors for MI at a young age [6]. Some authors, in addition to the aforementioned risk factors, distinguished dyslipidemia, arterial hypertension, and type 2 diabetes mellitus, and this was different from our results [7-9].

MI at a young age is much more common in men than in women. According to numerous studies a share of males varies from 71.5 to $100 \%$ in this cohort [10-14]. IHD in men manifests 7-10 years earlier than in women [15]. Women are less susceptible to developing MI at a young age due to the direct protec- tive effect of estrogens on the coronary arteries $[16,17]$.

A family history of premature IHD is an important independent risk factor for MI [18]. Young patients in comparison with the elderly are twice as likely to have first-line relatives with early manifestation of IHD $[6,19]$. A. Oliveira et al. established that the relative risk of developing MI in young patients with a family history of premature IHD was 1.84 (95\% CI 1.07-3.17) against their healthy peers [20]. Such patients were found out to have a more severe course of IHD and more pronounced violation of lipid metabolism, they also suffered from insulin resistance and obesity more frequently $[21,22]$. The high prevalence of this risk factor among young patients included in the study makes it possible to discuss probable genetic predisposition to the early development of IHD in this cohort.

Smoking is the only one potentially fully modifiable risk factor for IHD. Smoking plays an important role not only in the occurrence of cardiovascular diseases but also significantly contributes to their progression and poor prognosis. Smoking accelerates the development of atherosclerosis, causing damage to the vascular endothelium, reducing tissue oxygenation and increasing the activity of the sympathetic nervous system. In addition smoking promotes an increase in platelet aggregation activity and a decrease in HDLP levels [23, 24]. Smoking increases the risk of developing MI at a young age by 3.33 times whereas there is only 2.44 time increase caused by it in the elderly people [3]. It was noted that young patients smoked more cigarettes per day [25]. In a study made by A. Oliveira et al. the relative risk of MI was 4.56 (95 \% CI 2.32-9.0) among patients younger than 45 who smoked more than 15 cigarettes per day against young people who quit smoking [20]. These data confirm the persistent negative effects produced by smoking. Giving up smoking remains one of the most effective measures to prevent cardiovascular disease [24]. 
Conclusion. The data obtained in this study made it possible to form the risk factors profile of MI taking into account age characteristics. Risk factors associated with the development of MI at a young age include male gender, family history of premature IHD, and smoking. At the same time dyslipidemia, arterial hypertension, physical inactivity and obesity are also widespread among young patients and this is accompanied with developing endothelial dysfunction, early vascular aging and the formation of thrombophilic status in the hemostatic system.

Funding. The research was not granted any sponsor support.

Conflict of interests. The authors declare there is no any conflict of interests.

\section{References}

1. Krittanawong C., Liu Y., Mahtta D., Narasimhan B., Wang Z., Jneid H., Tamis-Holland J.E., Mahboob A. [et al.]. Non-traditional risk factors and the risk of myocardial infarction in the young in the US population-based cohort. Int. J. Cardiol. Heart Vasc., 2020, vol. 30, pp. e100634. DOI: 10.1016/j.ijcha.2020.100634

2. Egred M., Viswanathan G., Davis G.K. Myocardial infarction in young adults. Postgrad. Med. J, 2005, vol. 81, no. 962, pp. 741-745. DOI: 10.1136/pgmj.2004.027532

3. Yusuf S., Hawken S., Ounpuu S., Dans T., Avezum A., Lanas F., McQueen M., Budaj A. [et al.]. Effect of potentially modifiable risk factors associated with myocardial infarction in 52 countries (the INTERHEART study): case-control study. Lancet, 2004, vol. 364, pp. 937-952. DOI: 10.1016/S0140-6736(04)17018-9

4. Lisowska A., Makarewicz-Wujec M., Filipiak K.J. Risk factors, prognosis, and secondary prevention of myocardial infarction in young adults in Poland. Kardiol. Pol., 2016, vol. 74, no. 10. pp. 1148-1153. DOI: 10.5603/KP.a2016.0098

5. Zhang W., Yuan Z., Liu Y., Jia L., Cheng H., Qi J., Wu H., Wang Y., Wang D. [et al.]. Risk factors and coronary angiographic findings in young and elderly patients with acute myocardial infarction: a comparative analysis. Nan Fang Yi Ke Da Xue Xue Bao, 2008, vol. 28, no. 5, pp. 718-721 (in Chinese).

6. Hoit B.D., Gilpin E.A., Henning H., Maisel A.A., Dittrich H., Ross J.Jr. Myocardial infarction in young patients: an analysis by age subsets. Circulation, 1986, vol. 74, pp. 712-721. DOI: 10.1161/01.cir.74.4.712

7. Chan M.Y., Woo K.S., Wong H.B., Chia B.L., Sutandar A., Tan H.C. Antecedent risk factors and their control in young patients with a first myocardial infarction. Singapore Med. J., 2006, vol. 47 , pp. $27-30$.

8. Zimmerman F.H., Cameron A., Fisher L.D., Grace N. Myocardial infarction in young adults: angiographic characterization, risk factors and prognosis (Coronary Artery Surgery Study Registry). J. Am. Coll. Cardiol., 1995, vol. 26, pp. 654-661.

9. Incalcaterra E., Caruso M., Lo Presti R., Caimi G. Myocardial infarction in young adults: risk factors, clinical characteristics and prognosis according to our experience. Clin. Ter., 2013, vol. 164, pp. e77-82. DOI: 10.7417/CT.2013.1535

10. Popov S.V., Garganeeva A.A., Borel' K.N., Kuzheleva E.A., Okrugin S.A. Myocardial infarction in young patients: long-term analysis of appearance, clinical course and strategies of management. Kompleksnye problemy serdechno-sosudistykh zabolevanii, 2016, no. 4, pp. 66-72. DOI: 10.17802/2306-1278-2016-4-66-72 (in Russian).

11. Ponomarenko I.V., Sukmanova I.A. Clinical data and hemodynamic parameters in young adults with acute coronary syndrome. Kompleksnye problemy serdechno-sosudistykh zabolevanii, 2018, vol. 7, no. 1, pp. 14-20. DOI: 10.17802/2306-1278-2018-7-1-14-20 (in Russian).

12. Yandrapalli S., Nabors C., Goyal A., Aronow W.S., Frishman W.H. Modifiable Risk Factors in Young Adults With First Myocardial Infarction. J. Am. Coll. Cardiol., 2019, vol. 73, no. 5, pp. 573-584. DOI: 10.1016/j.jacc.2018.10.084

13. Deora S., Kumar T., Ramalingam R., Manjunath C.N. Demographic and angiographic profile in premature cases of acute coronary syndrome: analysis of 820 young patients from South India. Cardiovasc. Diagn. Ther., 2016, vol. 6, no. 3, pp. 193-198. DOI: 10.21037/cdt.2016.03.05 
14. Shiraishi J., Kohno Y., Yamaguchi S., Arihara M., Hadase M., Hyogo M., Yagi T., Shima T. [et al.]. Acute myocardial infarction in young Japanese adults: Clinical manifestations and in-hospital outcome. Circ. J., 2005, no. 69, pp. 1454-1458. DOI: 10.1253/circj.69.1454

15. Maas A., Appelman Y. Gender differences in coronary heart disease. Neth. Heart J., 2010, vol. 18, pp. 598-602. DOI: 10.1007/s12471-010-0841-y

16. Mendelsohn M.E., Karas R.H. The protective effects of estrogen on the cardiovascular system. N. Engl. J. Med., 1999, vol. 340, pp. 1801-1811. DOI: 10.1056/NEJM199906103402306

17. Subbiah M.T. Mechanisms of cardioprotection by estrogens. Proc. Soc. Exp. Biol. Med., 1998, vol. 217, no. 1, pp. 23-29. DOI: 10.3181/00379727-217-44201

18. Chow C.K., Islam S., Bautista L., Rumboldt Z., Yusufali A., Xie C., Anand S.S., Engert J.C. [et al.]. Parental history and myocardial infarction risk across the world: the INTERHEART Study. $J$. Am. Coll. Cardiol., 2011, vol. 57, pp. 619-627. DOI: 10.1016/j.jacc.2010.07.054

19. Hosseini S.K., Soleimani A., Karimi A.A., Sadeghian S., Darabian S., Abbasi S.H., Ahmadi S.H., Zoroufian A. [et al.]. Clinical features, management and in-hospital outcome of ST elevation myocardial infarction (STEMI) in young adults under 40 years of age. Monaldi Arch. Chest Dis., 2009, vol. 72, pp. 71-76. DOI: 10.4081/monaldi.2009.331

20. Oliveira A., Barros H., Azevedo A., Bastos J., Lopes C. Impact of risk factors for non-fatal acute myocardial infarction. Eur. J. Epidemiol., 2009, vol. 24, pp. 425-432. DOI: 10.1007/s10654-009-9352-9

21. Gaeta G., De Michele M., Cuomo S., Guarini P., Foglia M.C., Bond M.G., Trevisan M. Arterial abnormalities in the offspring of patients with premature myocardial infarction. N. Engl. J. Med., 2000, vol. 343, no. 12, pp. 840-846. DOI: 10.1056/NEJM200009213431203

22. Berenson G.S., Srinivasan S.R., Bao W., Newman W.P. 3rd, Tracy R.E., Wattigney W.A. Association between multiple cardiovascular risk factors and atherosclerosis in children and young adults. N. Engl. J. Med., 1998, vol. 338, no. 23, pp. 1650-1656. DOI: 10.1056/NEJM199806043382302

23. Broda G., Rywik S. Wieloośrodkowe ogólnopolskie badanie stanu zdrowia ludności - projekt WOBASZ [Multicenter nationwide population health survey - project YOU]. Kardiol. Pol., 2005, vol. 63, pp. 601-685 (in Polish).

24. Messner B., Bernhard D. Smoking and cardiovascular disease: mechanisms of endothelial dysfunction and early atherogenesis. Arterioscler. Thromb. Vasc. Biol., 2014, vol. 34, no. 3, pp. 509-515. DOI: 10.1161/ATVBAHA.113.300156

25. Barbash G.I., White H.D., Modan M., Diaz R., Hampton J.R., Heikkila J., Kristinsson A., Moulopoulos S. [et al.]. Acute myocardial infarction in the young - the role of smoking. The Investigators of the International Tissue Plasminogen Activator/Streptokinase Mortality Trial. Eur. Heart J., 1995, vol. 16, pp. 313-316.

Novikova I.A., Khlynova O.V., Nekrutenko L.A. Risk factors profile for myocardial infarction: focus at a young age. Health Risk Analysis, 2021, no. 3, pp. 155-161. DOI: 10.21668/health.risk/2021.3.16.eng

Received: 14.01.2021

Accepted: 27.07 .2021

Published: 30.09.2021 